J. Lake Sci. (湖泊科学), 2021, 33(1): 289-298

DOI 10. 18307/2021. 0121

(c) 2021 by Journal of Lake Sciences

\title{
洪泽湖水沙变化趋势和冲淤时空分布及驱动因素"
}

\author{
贲 鹏 ${ }^{1,2 * *}$, 虞邦义 ${ }^{1,2}$, 张 辉 ${ }^{1,2}$, 胡 勇 ${ }^{1,2}$ \\ ( 1 : 安徽省(水利部淮河水利委员会) 水利科学研究院,蚌埠 233000$)$ \\ $(2$ : 水利水资源安徽省重点实验室,蚌埠 233000)
}

\begin{abstract}
摘 要: 为了研究洪泽湖水沙特性、变化趋势与冲淤时空分布规律, 运用累积距平法、Mann-Kendall 趋势与突变检验以及 $\mathrm{R} / \mathrm{S}$ 分析法等方法,分析了洪泽湖 1950-2016 年的水沙特征; 采用地理信息技术, 基于 1992 年和 2016 年实测地形, 对湖 区泥沙冲淤空间分布进行了定量计算与分析. 结果表明, 人湖径流量无明显增加或减少的趋势, 输沙量和含沙量呈明显 减小趋势, 1990 年以后含沙量基本稳定在 $0.2 \mathrm{~kg} / \mathrm{m}^{3}$ 以下; 淮河干流 (包括池河) 人湖水量和沙量约占人湖总量的 $89.6 \%$, 三河闸出湖水沙占总出湖量的 $60 \%$. 淮干人湖口和溧河洼为主要淤积区域,淤积量分别为 $2300 \times 10^{4}$ 和 $1900 \times 10^{4} \mathrm{~m}^{3}$, 平均 淤积厚度分别为 0.35 和 $0.25 \mathrm{~m}$; 其他区域自然冲淤基本平衡. 上游水库和河道闸坝的拦沙作用、农业种植结构变化和水 土保持、大规模人工采砂等是人湖沙量减少的主要影响因素;湖区水动力特性是泥沙自然淤积主导因素,而湖区库容变 化的主因则是人工采砂、围湖造田和围网养殖,且人类活动的影响远大于自然冲淤.
\end{abstract}

关键词: 洪泽湖;水沙变化;湖盆演变;冲淤分布;驱动因素

\section{Spatiotemporal runoff and sediment variation, deposition-erosion characteristics and their driving factors in Lake Hongze *}

\author{
Ben Peng ${ }^{1,2 * *}$, Yu Bangyi ${ }^{1,2}$, Zhang Hui ${ }^{1,2} \& \mathrm{Hu}$ Yong $^{1,2}$ \\ (1: Anhui \& Huaihe River Institute of Hydraulic Research, Bengbu 233000, P.R. China) \\ (2: Key Laboratory of Water Conservancy and Water Resources of Anhui Province, Bengbu 233000, P.R.China)
}

\begin{abstract}
In order to study the water and sediment variation trend, changes in sediment deposition and erosion and spatial distribution of Lake Hongze, the methods of cumulative anomaly, Mann-Kendall trend and mutation test, and R/S analysis were used to analyze the water and sediment characteristics of Lake Hongze from 1950 to 2016. Using geographic information technology, based on the terrain of the lake area in 1992 and 2016, the spatial distribution of sediment erosion and siltation was quantitatively calculated and analyzed. The results show that, on the premise of no increasing or decreasing of the flow rate, the sediment transport and concentration show an obvious decreasing trend. After 1990, the sediment concentration has stabilized below $0.2 \mathrm{~kg} / \mathrm{m}^{3} ;$ The amount of water and sediment flowing into the mainstream of the Huaihe River (including the Chihe River) accounts for about $89.6 \%$ of the total amount of water flowing into the lake, and the outflow of Sanhe Sluice accounts for $60 \%$ of the total outflow. The main sedimentary areas of the Lake Huaihe inlet and Lihewa are the sedimentation volumes of $2300 \times 10^{4}$ and $1900 \times 10^{4} \mathrm{~m}^{3}$, and the average sedimentation thickness is 0.35 and $0.25 \mathrm{~m}$, respectively; Basic balance of natural erosion and deposition in other areas. The effects of the upstream reservoir sediment blocking, agricultural planting changing underlying surface, and artificial sand mining are the key reasons for the continuous decline of sediment concentration entering the lake. The hydrodynamic characteristics of the lake area are the dominant factors for the natural sedimentation of the sediment, while the main reasons for the change in the storage capacity of the lake area are artificial sand mining, lake farming, and seine culture, and the impact of human activities is far greater than that of natural erosion and deposition.
\end{abstract}

Keywords: Lake Hongze; water and sediment variation trend; lake basin evolution; erosion and deposition distribution; driving factors

\footnotetext{
* 2020-03-10 收稿; 2020-06-15 收修改稿.

国家重点研发计划项目 (2017YFC0405602) 和国家自然科学基金项目 (51809002) 联合资助.

** 通信作者;E-mail : benpeng11172219@126.com.
} 
洪泽湖位于淮河中游和下游的结合部, 承泄淮河上、中游 $15.8 \times 10^{4} \mathrm{~km}^{2}$ 流域面积的来水来沙, 是一座具 有防洪、蓄水、水产、航运和生态等综合利用功能的大型平原水库, 也是南水北调东线工程的重要输水通道. 洪泽湖属浅水湖, 湖盆呈浅碟形, 岸坡平缓, 湖底较平坦, 湖底高程一般在 $10 \sim 11 \mathrm{~m}$ 之间.

洪泽湖是淮河行洪、蓄洪的重要载体, 淮河中游洪涝与洪泽湖的形成与扩大有直接的联系. 淮河干流河 道与洪泽湖是一对矛盾的统一体, 表现出复杂的互馈关系, 淮河干流水沙条件决定了洪泽湖冲淤演变规律, 而洪泽湖是淮河干流的侵蚀基准面, 较高的湖区水位导致淮河洪水下泄不畅,成为淮河严重洪涝灾害的主 要原因之一. 洪泽湖来水来沙变化趋势和冲淤时空分布规律研究主要涉及以下问题, 在自然和人类活动影 响下,洪泽湖水沙和冲淤如何变化? 如何量化这些变化? 是否具有趋势性? 未来的情势如何? 变化的原因 是什么? 这些变化与河床和湖盆演变关系如何? 维持河床与湖盆形态稳定性条件是什么? 这些的基础科 学研究对新时期解决淮河中游洪涝灾害, 探讨淮河与洪泽湖的关系、湖区综合治理、水资源保护利用等关键 问题的意义重大.

目前, 关于湖泊水沙变化规律及冲淤特性研究较多, 多集中在鄱阳湖和洞庭湖, 而洪泽湖相关研究较少. 代稳等 ${ }^{[1]}$ 对洞庭湖降水量、径流量和输沙量之间的相互关系进行分析, 确定影响水沙变化的驱动因素; 罗蔚 等 ${ }^{[2]}$ 分析了鄱阳湖水沙变化特征并初步探讨了水沙变化规律; 邓吉秋 等 $^{[3]}$ 基于 GIS 对目平湖泥沙冲淤变化 进行空间定量分析; 高俊峰等 ${ }^{[4]}$ 研究表明, 洞庭湖近 $24 \mathrm{a}$ 来总的趋势是淤积的, 局部有冲刷, 但总体上淤积 量大于冲刷量. 针对淮河与洪泽湖冲淤演变研究主要集中在降雨径流变化特性和沙量平衡冲淤计算方面, 孙鹏等 ${ }^{[5]}$ 分析了淮河流域中上游径流年内分配、年际变化、径流趋势、突变特征及周期变化等径流过程变化 特征; 刘源等 ${ }^{[6]}$ 分析了洪泽湖人湖水沙的周期性变化; 虞邦义等 ${ }^{[7]}$ 基于实测水沙资料, 得到洪泽湖区泥沙冲 淤情况. 目前, 基于洪泽湖长系列水沙资料的径流、泥沙变化规律探究较少, 也尚未见运用 GIS 技术对洪泽 湖泥沙冲淤时空分布进行定量研究.

本文采用长序列水沙资料和最新地形数据, 通过累积距平法、Mann-Kendall ( M-K)、R/S 分析法等解析 洪泽湖水沙的组成、时空演变规律, 并预测其变化趋势; 采用 GIS 数据处理方法分析洪泽湖泥沙冲淤量和空 间分布以及人湖水沙变化和冲淤分布的主要驱动因素, 揭示自然因素和人类活动耦合作用下洪泽湖冲淤格 局的时空演变规律及响应关系.

\section{1 水沙时空分布规律}

\section{1 河流水系情况}

洪泽湖人湖河流主要有淮河干流、池河、怀洪新河、新油河、濉河、老濉河和徐洪河等, 大多分布于湖区 的西北部; 出湖河道主要有人江水道、人海水道、分淮人沂、苏北灌溉总渠, 均位于湖区东南部. 洪泽湖水系 概化见图 1.

\section{2 入湖水沙历史变化趋势}

淮河干流是洪泽湖最大的来水来沙河道, 吴家渡水文站是距离洪泽湖最近的长系列水文资料观测站 点, 其水沙系列可以反映洪泽湖人湖水沙特性及变化规律. 由图 2 可知, 吴家渡站近 $66 \mathrm{a}$ 来, 多年平均径流 量为 $266.10 \times 10^{8} \mathrm{~m}^{3}$, 各年代平均径流量整体上呈现交替状态, 并无明显增加或减少的趋势; 多年平均输沙量 为 $827.02 \times 10^{4} \mathrm{t}$, 各年代平均输沙量随时间推移均呈明显减小趋势, 以 $22.882 \times 10^{4} \mathrm{t} / \mathrm{a}$ 的速率减少, 且输沙量 在 1985 年后整体上均低于近 $66 \mathrm{a}$ 平均值; 多年平均含沙量为 $0.28 \mathrm{~kg} / \mathrm{m}^{3}$, 各年代平均含沙量随时间推移均 呈明显减小趋势, 以 $0.0074 \mathrm{~kg} /\left(\mathrm{m}^{3} \cdot \mathrm{a}\right)$ 的速率减少, 1990 年以后含沙量基本稳定在 $0.2 \mathrm{~kg} / \mathrm{m}^{3}$ 以下.

\section{3 入湖泥沙变异性}

\subsection{1 分析方法 1) 累积距平法}

累积距平法是由曲线直观判断离散数据点变化趋势的一种非线性统计方法, 根据曲线上下起伏特性, 可以判断序列要素长期显著的变化趋势及持续性变化, 同时也还可以判断出发生突变的大致时间 ${ }^{[8]}$.

对于某一序列 $x$, 其某一时刻 $t$ 的累积距平表示为:

$$
\hat{X}_{t}=\sum_{i=1}^{t}\left(X_{i}-\bar{X}\right) \quad(t=1,2,3, \cdots, n)
$$




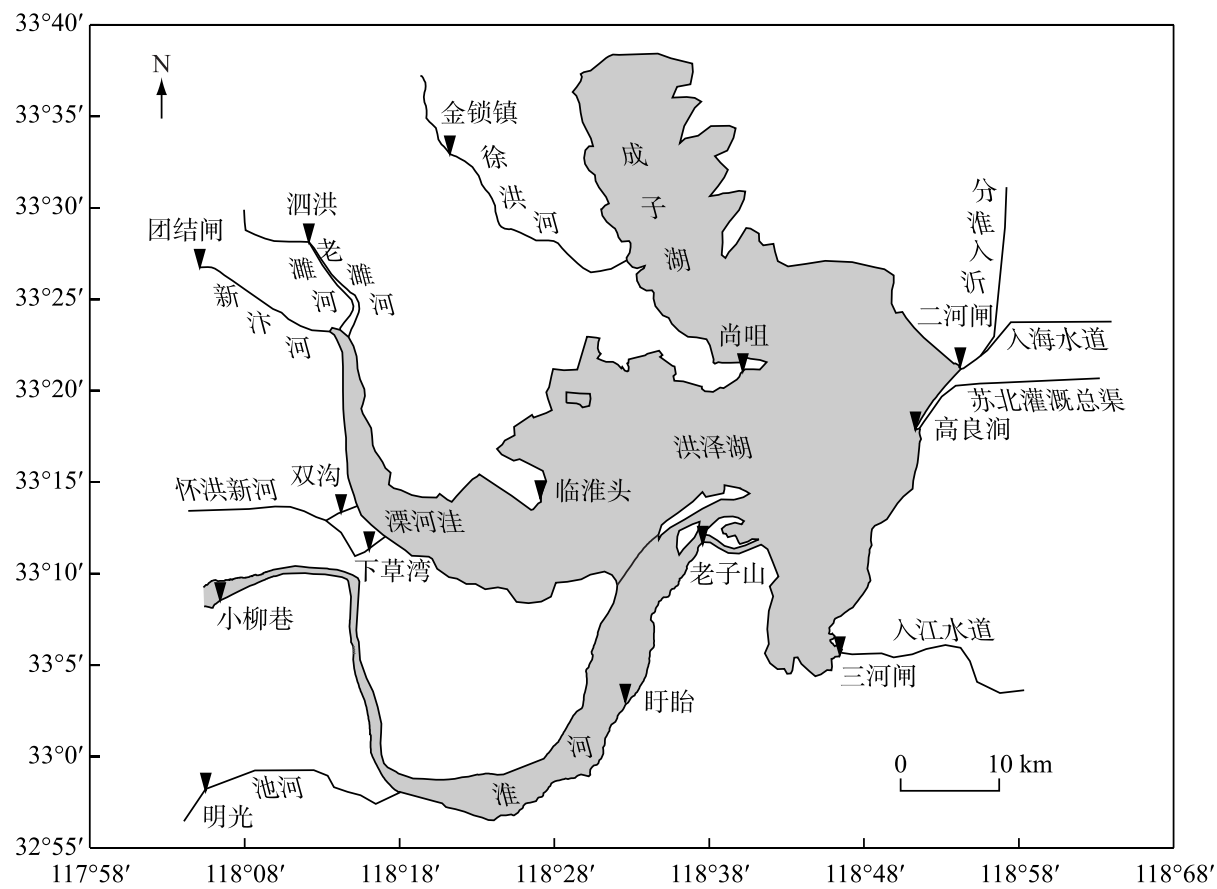

图 1 洪泽湖水系概化图

Fig.1 Water system generalization of Lake Hongze

式中, $\bar{X}$ 为序列的平均值, $\bar{X}=1 / t\left(\sum_{i=1}^{t} X_{i}\right) ; t$ 为时间.

\section{2) M-K 分析法}

M-K 分析法适用于不符合正态分布的水沙数 据, 不受少数异常值的干扰, 计算简便 ${ }^{[9]}$.

对于具有 $r_{i}$ 个样本量的时间序列 $x$,构造一秩 序列:

$$
S_{k}=\sum_{i=1}^{k} r_{i} \quad(k=2,3,4, \cdots, n)
$$

式中, $S_{k}$ 为第 $i$ 时刻数值大于第 $j$ 时刻数值个数的 累计数, $r_{i}$ 为第 $i$ 个样本 $x_{i}$ 大于 $y_{i}(1 \leqslant j \leqslant i)$ 的累 计数.

将 $S_{k}$ 标准化得到如下统计量:

$$
\begin{aligned}
U F_{k}= & \left(S_{k}-E\left(S_{k}\right)\right) / \sqrt{\operatorname{var}\left(S_{k}\right)} \\
& (k=1,2,3,4, \cdots, n)
\end{aligned}
$$

式中, $U F_{1}=0, E\left(S_{k}\right)$ 和 $\operatorname{var}\left(S_{k}\right)$ 分别为 $S_{k}$ 的均值 和方差. 给定显著性水平 $\alpha$, 若 $\left|U F_{k}\right|>U_{\alpha / 2}$, 则表 明时间序列存在明显的变化趋势.

将时间序列 $x$ 按逆序重复上述步骤, 同时使：

$$
U B_{k}=-U F_{k} \quad(k=n, n-1, n-2, \cdots, 1) \quad(4)
$$

通过对 $U B_{k}$ 和 $U F_{k}$ 曲线的分析, 得到突变时间 与突变区域.
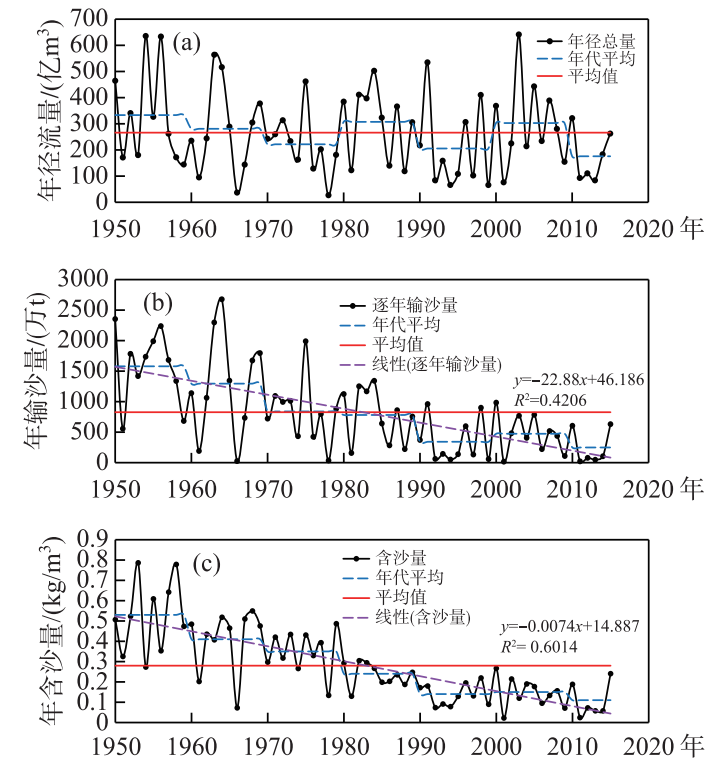

图 2 吴家渡站径流量 (a)、输沙量 (b) 和 含沙量 $(\mathrm{c})$ 的逐年变化

Fig. 2 Changes in the annual runoff (a), sediment discharge (b) and sediment concentration (c) at the Wujiadu Station 
1.3.2 变异性规律 采用累积距平法对吴家渡站年均来沙量进行多沙一少沙变化规律分析, 年输沙量与年含 沙量多沙一少沙变化过程基本相同,1980s 前为多沙期, 随后转人少沙期 (图 3). 采用 M-K 法对来沙序列进 行突变检验, 来沙量的 $U F_{k}$ 值整体都为负值, 表明来沙量一直处于减少的趋势, 减少趋势显著, 突变发生在 1980s(图 4).

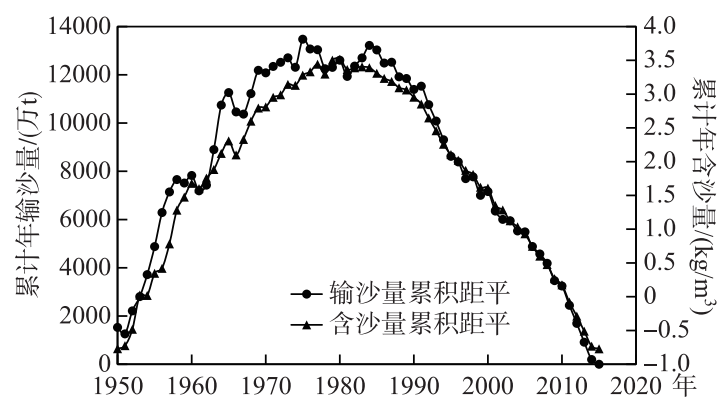

图 3 来沙量累积距平曲线

Fig.3 Cumulative anomaly curve of incoming

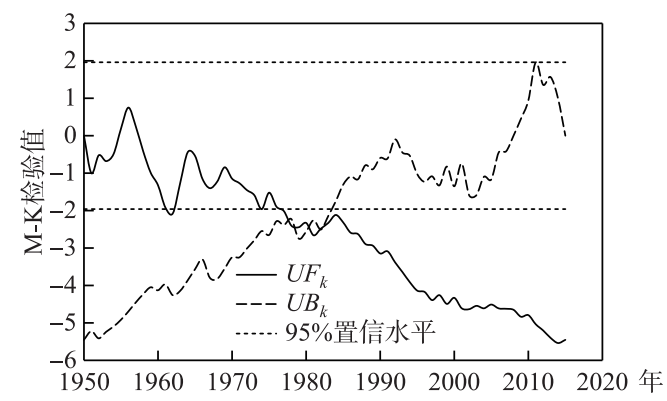

图 4 来沙量 M-K 法统计量曲线

Fig.4 Statistic curve of M-K method in sand volume

\section{4 入湖泥沙未来变化趋势}

1.4.1 分析方法 $\mathrm{R} / \mathrm{S}$ 分析法最先是由英国水文家 Hurst 提出的一种基于长程相关思想的时间序列统计方 法,已发展为一种广泛应用的趋势分析方法 ${ }^{[10]}$, 其基本原理如下:

考虑一个时间序列 $\{\xi(t)\}, t=1,2, \cdots$. 对于任意正整数 $\tau \geqslant 1$, 定义均值序列为:

$$
\langle\xi\rangle_{t}=\frac{1}{\tau} \sum_{i=1}^{\tau} \xi(t) \quad(\tau=1,2,3,4, \cdots, n)
$$

累积离差 $X(t, \tau)$ 为:

$$
X(t, \tau)=\sum_{u=1}^{t}\left(\xi(u)-\langle\xi\rangle_{t}\right) \quad(1 \leqslant t \leqslant \tau)
$$

极差 $R(\tau)$ 为:

$$
R(\tau)=\max _{1 \leqslant t \leqslant \tau} X(t, \tau)-\min _{1 \leqslant t \leqslant \tau} X(t, \tau) \quad(\tau=1,2,3,4, \cdots, n)
$$

标准差 $S(\tau)$ 为:

$$
S(\tau)=\left\{\frac{1}{\tau} \sum_{i=1}^{\tau}\left[\sum_{u=1}^{t}\left(\xi(t)-\langle\xi\rangle_{t}\right]^{2}\right\}^{1 / 2} \quad(\tau=1,2,3,4, \cdots, n)\right.
$$

研究发现:

$$
R(\tau) / S(\tau)=K(\tau / 2)^{H}
$$

式中, $K$ 为比例系数, $H$ 为 Hurst 指数.

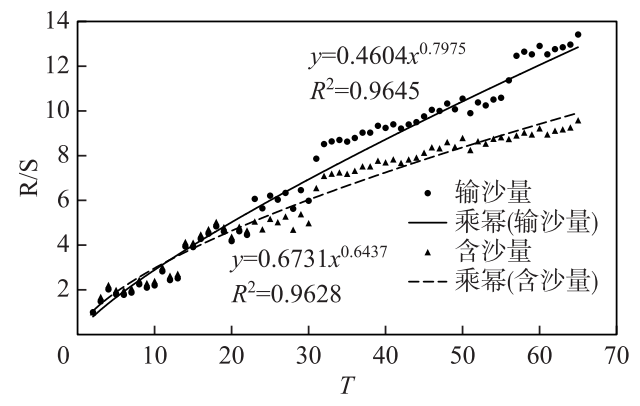

图 5 吴家渡站来沙量 $\mathrm{R} / \mathrm{S}$ 法统计量曲线

Fig.5 R/S statistic curve of incoming sand volume at the Wujiadu Station
1.4 .2 变化趋势分析 采用 $\mathrm{R} / \mathrm{S}$ 分析法对吴家渡站未来 一段时间内来沙趋势进行判断. 由图 5 可知, 来沙量时间 序列 $\mathrm{R} / \mathrm{S}$ 法统计量 $H$ 回归拟合程度较好, 输沙量、含沙量 与历时的相关系数 $R^{2}$ 分别可达到 0.9645 和 0.9628 . 输沙 量和含沙量时间序列的 Hurst 指数均大于 0.5 , 表明未来 一段时间输沙过程具有持续性, 且与历时有正相关性, 即 未来变化趋势将和输沙量历史总体趋势保持相同.

\section{5 入出湖水沙空间分布}

淮河干流小柳巷站是距离洪泽湖最近的水文站, 于 1982 年建站, 能够更好地反映近期淮河干流人洪泽湖水 沙量, 以其近 $34 \mathrm{a}$ 的水沙系列分析人、出湖水沙空间分 
布, 对于个别年份缺测资料进行了相关插补 ${ }^{[13]}$. 由表 1 可知, 1983-2016 年淮河 (淮河干流和池河) 来水来 沙量均占人湖总量的 $89.6 \%$, 平均含沙量为 $0.19 \mathrm{~kg} / \mathrm{m}^{3}$; 怀洪新河来水量占 $5.7 \%$, 来沙量仅占 $1.5 \%$, 平均含 沙量为 $0.05 \mathrm{~kg} / \mathrm{m}^{3}$, 怀洪新河下游地区地势低洼, 湖泊、河道众多, 泥沙沉积后人湖量较小; 溧河洼西北支流 来水量占 $3.8 \%$, 来沙量占 $6.5 \%$, 平均含沙量为 $0.33 \mathrm{~kg} / \mathrm{m}^{3}$, 含沙量较大. 由表 2 可知, 三河闸是水沙出湖的主 要通道, 约 $60 \%$ 水沙量经人江水道排人长江, 未考虑蒸发和取用水. 洪泽湖水沙同源, 输沙量的大小受控于 来水量大小,符合大水大沙的特点.

表 1 1983-2016 年洪泽湖人湖水沙空间分布

Tab.1 Spatial distribution of water and sediment in Lake Hongze from 1983 to 2016

\begin{tabular}{|c|c|c|c|c|c|}
\hline \multirow{2}{*}{ 项目 } & \multirow{2}{*}{ 总人湖量 } & 淮河 & 怀洪新河 & 溧河洼西北部支流 & \multirow{2}{*}{ 其他 } \\
\hline & & 淮干+池河 & 双沟+下草湾 & 新泣河+老濉河+濉河 & \\
\hline 多年平均水量 $/\left(\times 10^{8} \mathrm{~m}^{3}\right)$ & 296.8 & 266.1 & 16.9 & 11.2 & 2.6 \\
\hline 占总水量比例/\% & & 89.5 & 5.7 & 3.8 & 0.9 \\
\hline 多年平均沙量 $/\left(\times 10^{4} \mathrm{t}\right)$ & 580.9 & 527.2 & 8.4 & 37.4 & 7.9 \\
\hline 占总沙量比例/\% & & 90.7 & 1.5 & 6.5 & 1.3 \\
\hline
\end{tabular}

表 2 1983-2016 年洪泽湖出湖水沙空间分布

Tab.2 Spatial distribution of water and sediment out of Lake Hongze from 1983 to 2016

\begin{tabular}{cccccc}
\hline 项目 & 总出湖量 & 人江水道 & 人海水道+分淮人沂 & 苏北灌溉总渠 & 其他 \\
\hline 多年平均水量 $/\left(\times 10^{8} \mathrm{~m}^{3}\right)$ & 276.8 & 160.8 & 76.1 & 39.9 & 0 \\
占总水量比例 $/ \%$ & & 58.0 & 27.0 & 14.0 & 0 \\
多年平均沙量 $/\left(\times 10^{4} \mathrm{t}\right)$ & 280.1 & 184.4 & 69.8 & 25.7 & 0 \\
占总沙量比例 $/ \%$ & & 62.1 & 23.5 & 8.7 & 0 \\
\hline
\end{tabular}

\section{2 输沙平衡冲淤分析}

\section{1 近期冲淤年际分布规律}

根据洪泽湖人湖和出湖控制站计算出湖区年际泥沙冲淤量, 冲淤年际分布见图 6. 洪泽湖 1983-2016 年 总体趋势是淤积, 总来沙量为 $19726.8 \times 10^{4} \mathrm{t}$, 出沙量为 $9522.5 \times 10^{4} \mathrm{t}$, 淤积量为 $10204.8 \times 10^{4} \mathrm{t}$, 淤积率为 $51.7 \%$, 多年平均淤积量为 $300.1 \times 10^{4} \mathrm{t}$, 其中 2007 年淤积量最大, 为 $1044.4 \times 10^{4} \mathrm{t}$. 系列资料 $34 \mathrm{a}$ 中 $2001 、 2009 、 2011$ 、 2012 年发生微冲, 冲刷量都小于 $50 \times 10^{4} \mathrm{t} ; 1994$ 和 2014 年输沙基本平衡; 1992、1993、1995、1997 和 1999 年共5 a 发生微淤,淤积量小于 $100 \times 10^{4} \mathrm{t}$,其余 $23 \mathrm{a}$ 洪泽湖都发生淤积,淤积量大于 $100 \times 10^{4} \mathrm{t}$.

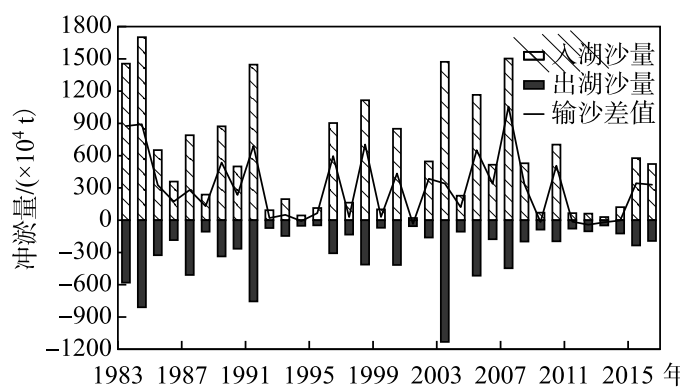

图 6 洪泽湖年际冲淤分布

Fig.6 Interannual scouring and deposition of Lake Hongze 


\section{2 长系列冲淤量及变化趋势}

文献 [7]推算了 1950-1959 年、1966-1976 两个时段的洪泽湖冲淤量; 文献[12]计算了 1960-1965 年、1972-1982 年两个时段的洪泽湖冲淤量; 结合近期水沙资料,进一步推算出 1950-2015 年洪泽湖总淤 积量为 $30174 \times 10^{4} \mathrm{t}$, 年均淤积 $457 \times 10^{4} \mathrm{t}$. 从表 3 可以看出, 洪泽湖淤积量呈减少趋势, 洪泽湖淤积量减少与 淮河干支流来沙量变化趋势一致.

表 3 洪泽湖各年代平均淤积量

Tab.3 Average sedimentation of Lake Hongze in each age

\begin{tabular}{cccccccc}
\hline 年份 & $1950-1959$ & $1960-1969$ & $1970-1979$ & $1980-1989$ & $1990-1999$ & $2000-2009$ & $2010-2015$ \\
\hline 年均淤积量 $/\left(\times 10^{4} \mathrm{t}\right)$ & 874 & 650 & 465 & 404 & 241 & 357 & 44 \\
\hline
\end{tabular}

\section{3 湖盆冲淤分布规律}

以 1992 年( $1: 10000$ 地形图, 1985 国家高程)和 2016 年 (1:10000 地形图, 1985 国家高程) 实测地形图为 研究的基础数据,基于 GIS 的泥沙冲淤变化空间定量分析和地理空间数据,运用数字化、GIS 的数据处理和空 间分析功能,实现对不同时间泥沙淤积状态的计算与对比,从而对泥沙冲淤的空间分布变化进行计算与分析.

\section{1 冲淤高程分布特征}

本次仅分析洪泽湖湖区 $13.5 \mathrm{~m}$ 高程以下湖盆的冲淤变化, 不包含周边滞洪圩区及湖泊洼地. 湖区 1992 年高程见图 7a, 2016 年高程见图 7b,1992 和 2016 年库容变化见表 4, 可以看出, 整个湖区库容增加 $0.91 \times 10^{8}$ $\mathrm{m}^{3}$, 包括采砂量和航道疏浚量. $9.5 \mathrm{~m}$ 高程以下湖区变化最大, 库容增加 $0.92 \times 10^{8} \mathrm{~m}^{3}$, 主要变现为局部深坑; $10.5 \mathrm{~m}$ 高程以下库容增加 $1.29 \times 10^{8} \mathrm{~m}^{3}, 9.5 \sim 10.5 \mathrm{~m}$ 高程区域库容增加 $0.37 \times 10^{8} \mathrm{~m}^{3}$, 主要变现为局部深坑和 航道变化; $11.5 \mathrm{~m}$ 高程以下库容增加 $0.71 \times 10^{8} \mathrm{~m}^{3}, 10.5 \sim 11.5 \mathrm{~m}$ 高程区域库容减少 $0.58 \times 10^{8} \mathrm{~m}^{3}$, 说明该区域 发生了淤积; $11.5 \sim 13.5 \mathrm{~m}$ 之间湖区库容变化较小, 冲淤幅度较小.

2016 年湖底出现较多深坑, 局部区域下切近 $6 \mathrm{~m}$, 初步分析, 湖区深坑不是自然冲淤的结果, 而是人工采 砂造成的 ${ }^{[13]}$. 为了反映湖区真实冲淤量, 需要对局部 DEM 地形进行修正, 扣除明显的采砂坑和航道疏浚量 后, 湖区表现为淤积, 淤积量为 $4200 \times 10^{4} \mathrm{~m}^{3}$, 平均淤积厚度为 $0.03 \mathrm{~m}$. 航道整治方量修正计算方法, 以 2016 年地形航道边界为基准,将航道区域冲淤量设置为 $0 \mathrm{~m}^{3}$; 人工采砂量周边修正计算方法,将采砂坑周边局部 静水或流速较小且冲刷厚度大于 $0.3 \mathrm{~m}$ 区域的冲刷量设置为 $0 \mathrm{~m}^{3}$.
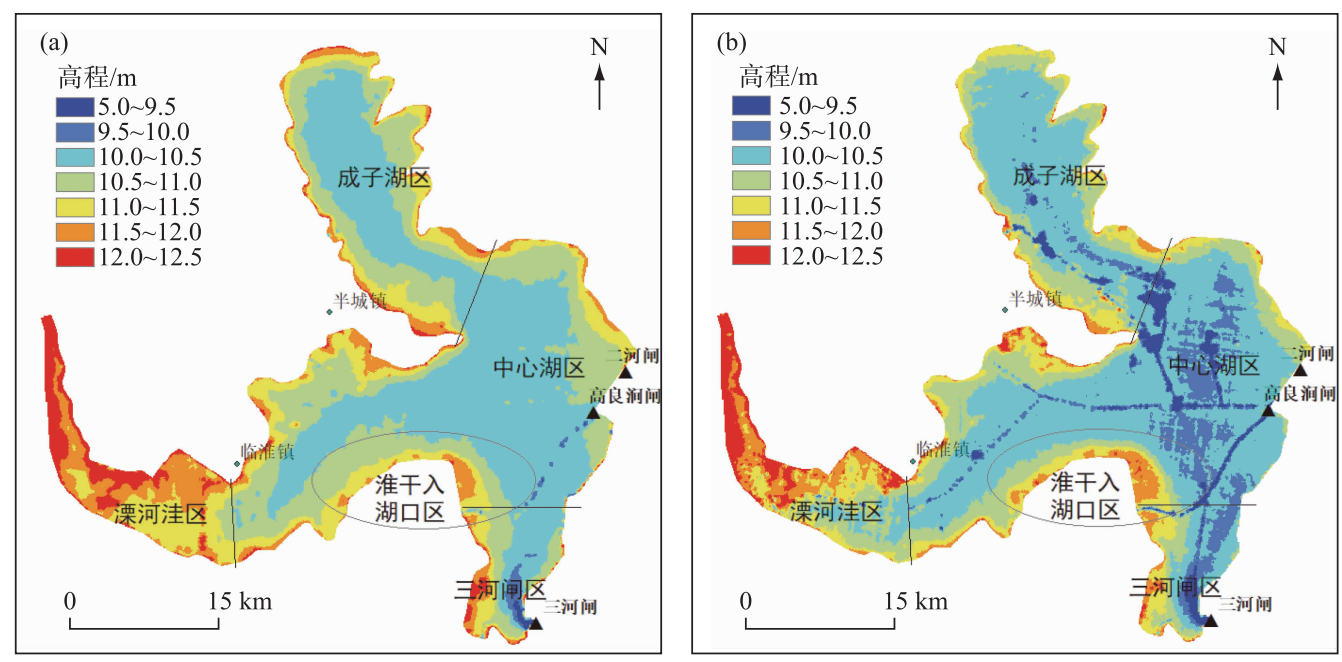

图 7 洪泽湖湖区 1992 年 (a) 和 2016 年(b)高程

Fig.7 Elevations of Lake Hongze in 1992 (a) and 2016 (b) 
表 4 各高程湖区库容及变化量 $\left(\times 10^{8} \mathrm{~m}^{3}\right)$

Tab.4 Storage capacity and erosion and variation of each elevation lake area $\left(\times 10^{8} \mathrm{~m}^{3}\right)$

\begin{tabular}{cccccc}
\hline & & & & \\
& & & & \\
& 13.5 & 12.5 & 11.5 & 10.5 & 9.5 \\
\hline 1992 年 & 37.49 & 24.70 & 12.52 & 3.54 & 0.60 \\
2016 年 & 38.40 & 25.62 & 13.23 & 4.83 & 1.52 \\
变化量 & 0.91 & 0.92 & 0.71 & 1.29 & 0.92 \\
\hline
\end{tabular}

\section{2 冲淤空间分布特征}

湖区不同区域的形态和水流特性相差较大, 冲淤 变化亦不同,根据人、出流位置和湖区形态将湖盆分为 5 个区域,分别为淮干人湖口区、溧河洼区、成子湖区、 三河闸区和中心湖区 (图 8). 淤积区域主要集中在淮 干人湖口、溧河洼以及临淮镇和半城镇局部区域;成子 湖和三河闸区冲淤幅度较小,局部回淤; 中心湖区冲淤 总体表现为冲刷, 冲刷量较小. 淮干人湖口区淤积量约 为 $2300 \times 10^{4} \mathrm{~m}^{3}$, 局部淤积厚度达 $1.0 \mathrm{~m}$, 平均淤积厚度 为 $0.35 \mathrm{~m}$. 溧河洼主要淤积在怀洪新河人湖口以上湖 区, 淤积量约为 $1900 \times 10^{4} \mathrm{~m}^{3}$, 平均淤积厚度为 $0.25 \mathrm{~m}$; 怀洪新河人湖口以下湖区未淤积, 有微冲. 临淮镇和半 城镇等局部区域淤积约为 $900 \times 10^{4} \mathrm{~m}^{3}$. 中心湖区总体 表现为冲刷, 西部冲淤基本平衡, 东部湖区湖底下切, 下切深度为 $0.1 \sim 0.2 \mathrm{~m}$, 库容约增加 $1600 \times 10^{4} \mathrm{~m}^{3}$, 由于 区域内采砂严重, 库容增加并非自然冲刷的结果.

\section{3 地形法与输沙法对比}

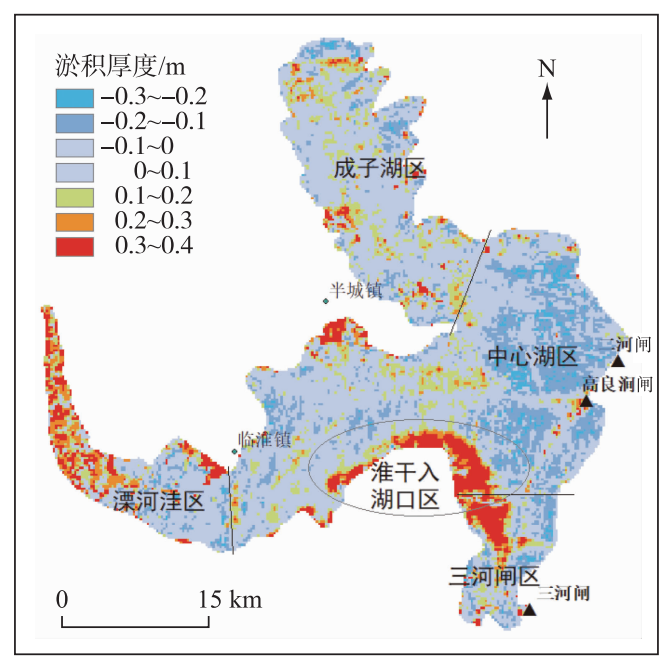

图 8 湖区冲淤空间分布 (+为淤积; - 为冲刷)

Fig. 8 Spatial distribution of erosion and deposition in the lake area $(+$ : deposition; - : scour $)$

按地形法计算, 1992- 2016 年间,扣除人工采砂 和航道疏浚量后, 湖区表现为淤积, 淤积区域为淮干人湖口和溧河洼区西北部, 淤积量为 $4200 \times 10^{4} \mathrm{~m}^{3}$, 这两 个区域是湖区沙源所在. 按输沙法计算, 1992-2016 年间, 湖区共淤积 $5600 \times 10^{4} \mathrm{t}$, 相当于淤积量为 $3700 \times$ $10^{4} \mathrm{~m}^{3}$. 两种计算方法结果基本吻合, 也可以说明洪泽湖来沙主要淤积在淮干人湖口和溧河洼区域, 其他湖 区冲淤基本平衡.

\section{4 水沙变化和湖盆演变驱动因素}

\section{1 水沙变化趋势原因分析}

出湖水沙特性受人湖水沙、降雨、蒸发、湖区冲淤、水资源利用等因素影响,其核心因素是人湖水沙条 件,这里仅分析入湖水沙变化原因.

1) 洪泽湖人湖水量变化的主导因素为天然降雨. 1950s 以来,洪泽湖流域面雨量呈波动增加趋势, 但是 总体变化趋势不明显 ${ }^{[11,14-15]}$, 流域用水总量虽然呈现缓慢增长趋势, 但增长缓慢, 并且增加量主要源于地下 水 ${ }^{[18]}$. 面雨量和用水量均没有发生明显变化, 洪泽湖人湖水量也无明显变化趋势.

2) 流域大型水库和河道闸坝的蓄水拦沙是人湖沙量减少的重要原因 ${ }^{[16]}$. 淮河上游山区和淮北平原水 系是淮河流域的主要产流产沙区, 1970s 建成了五岳、泼河和鲇鱼山水库, 1987 年板桥水库复建, 1993 年石 漫滩水库复建, 随着水库库容的增加, 拦沙作用更为明显, 使得上游泥沙淤积在水库中, 淮河中游河道含沙 量减小. 1990s,淮河水系水库和闸坝建设基本完成, 区域来沙也基本稳定下来.

3) 农业种植结构改变和水土保持改变了流域下垫面 ${ }^{[17]}$. 淮北平原是我国重要的粮食生产基地,淮北支 
流洪汝河、沙颖河来沙量对淮河干流影响较大. 1980s 开始, 为了增加粮食产量, 采用精耕细作、涵养水分和 养分、增加复种指数等措施, 这些技术措施正是水土保持的第一道防线. 同时, 种植结构也发生一些变化, 如 旱地作物向水田作物转变、粮食作物向经济作物转变等,地面裸土面积减小,改变了淮北地区的下垫面. 同 时, 治淮骨干工程要求进一步加大水土保持工程建设, 水土流失得到了有效的遏制, 使得淮河干流含沙量继 续减小.

4) 人工采砂直接影响人湖沙量, 而且改变河床形态. 1980s 中后期, 淮河干流及主要支流河道开始大规 模采砂, 根据淮干历次地形及历史水沙资料计算分析, 仅淮河干流王家坝至浮山段河道人工采砂量约为 $2 \times$ $10^{8} \mathrm{~m}^{3}$, 无序采砂导致河床出现大量不连续的深坑,河道成为沉砂池.

\section{2 湖盆演变原因分析}

2016 年较 1992 年洪泽湖 $13.5 \mathrm{~m}$ 高程以下库容增加 $9100 \times 10^{4} \mathrm{~m}^{3}$, 而大部分区域表现为淤积或者冲淤基 本平衡, 仅局部区域出现深坑, 湖区不同区域冲淤特性差别较大, 导致这种现象的主要原因如下:

1) 湖区水动力特性是泥沙自然淤积分布的重要影响因素 ${ }^{[18]}$. 湖区泥沙淤积区域为淮河干流人湖口和 溧河洼北部, 是湖区最大的两个来水来沙区. 淮河干流人湖口水面突然开阔, 人湖河段河底倒比降, 洪水期 河道段流速为 $1 \sim 2 \mathrm{~m} / \mathrm{s}$, 进入湖区扩散段后流速降至 $0.5 \mathrm{~m} / \mathrm{s}$ 以下, 水动力条件减弱, 挟沙能力明显下降, 导 致河口泥沙累积性淤积,特别是人湖河口淤积浅滩发育.

2) 围湖造田和围网养殖是洪泽湖局部淤积的重要原因. 洪泽湖的圈圩旺殖和围网养殖始于 $1960 \mathrm{~s}$, 在高 程 $12.5 \mathrm{~m}$ 以下的滩地进行圈地种植, 主要分布在溧河洼湖区、淮干人湖口、临淮镇和半城镇等西北湖区, 这 些区域正是湖区的淤积位置. 圈圩怎殖和围网养殖不仅占用洪泽湖库容, 而且严重阻水, 成为泥沙的沉积 区, 这也是淮干人湖口和溧河洼湖区泥沙淤积的重要原因. 1980s 以来, 洪泽湖西岸临淮镇附近的湖泊变化 最大, 大部分湖泊已经被变成了围网养殖区 ${ }^{[19]}$, 从航拍图片 (图9)来看, 近岸的湖面被隔堤和渔网切割成一 个个小块, 向内湖延伸近千米.

3) 人工采砂是影响湖区库容的主要因素之一. 中心湖区东部出现大量深坑, 且湖底出现大面积下切, 此 区域并非主流区, 不会出现大范围冲刷, 原因是人工采砂 ${ }^{[13]} .2005$ 年, 洪泽湖开始出现采砂; 2006 年,采砂区 域向洪泽湖水域纵深发展; 2010 年, 采砂区域扩大至泗洪、泗阳等多水域;2015 年, 采砂区域扩大整个湖区, 采砂船已增加到 600 余条 (图 10). 随着采砂区域不断扩大和采砂船数量不断增加, 大规模采砂活动对湖区 库容产生较大影响. 1992-2016 年, 洪泽湖采砂量超 $1 \times 10^{8} \mathrm{~m}^{3}$, 除采砂区域,期间洪泽湖表现为淤积或冲淤 基本平衡状态, 人类活动的影响远大于自然冲淤.

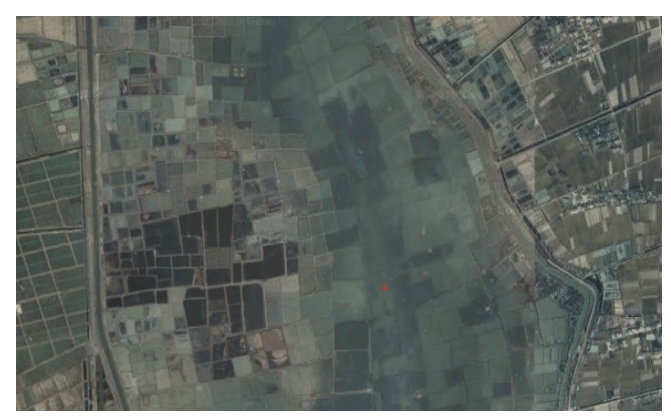

图 9 溧河洼围网养殖航拍图

Fig.9 Aerial photography of seine culture in Lihewa

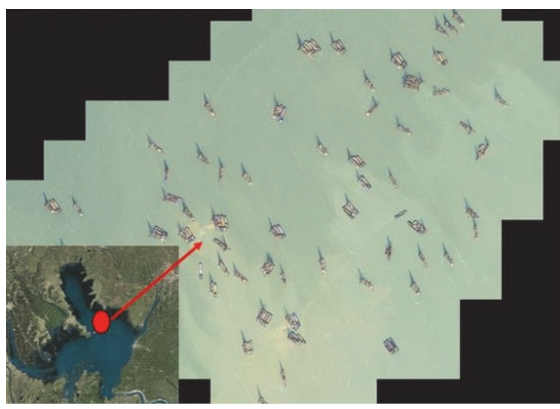

图 102014 年洪泽湖局部水域采砂航拍图

Fig.10 Aerial photo of sand mining in Lake Hongze in 2014

\section{5 结语与探讨}

1) 基于洪泽湖 1950-2016 年的实测水沙资料以及 1992 年和 2016 年地形资料,对其水沙变化趋势和湖 区冲淤分布进行了定量计算与定性分析. 结果表明, 洪泽湖人湖水量无明显增加或减少的趋势, 输沙量和含 
沙量呈明显减小趋势, 淮河干流 (包括池河) 人湖水量和沙量约占人湖总量的 $89.6 \%$; (2) 淮河干流人湖口和 溧河洼上部为主要淤积区域, 平均淤积厚度 0.35 和 $0.25 \mathrm{~m}$, 其他区域自然冲淤基本平衡; (3) 水库和道闸坝 的拦沙作用, 农业种植结构变化, 水土保持、大规模采砂等因素导致人湖沙量减少; 湖区水动力特性是泥沙 自然淤积的主导因素, 而湖区库容变化的主因则是人工采砂、围湖造田和围网养殖, 且人类活动的影响远大 于自然冲淤.

2) 1992-2016 年间,在自然和人类活动作用下, 淮干人湖口和溧河洼区域出现淤积,但淤积厚度不大; 湖区冲淤基本平衡, 淮干人湖口至三河闸、淮干人湖口至二河闸和怀洪新河人湖口至二河闸等以及湖区主 要流路也没有出现淤积现象. 根据人湖水沙变化规律, 在流域下垫面不发生较大变化条件下, 人湖含沙量将 维持在较低水平, 淤积量也将处于较低水平. 洪泽湖综合整治涉及湖区疏浚, 河床稳定性以及人海水道、人 江水道、冯铁营引河和老河道如何衔接等问题, 水沙变化趋势和冲淤时空分布规律可以为湖区综合治理提 供参考.

\section{6 参考文献}

[ 1 ] Dai W, Lv DQ, Li JB et al. Evolution characteristics and driving factors of runoff and sediment changes in Dongting Lake During 1951-2014. Journal of Soil and Water Conservation, 2017, 31(2): 142-150, 176. [代稳, 吕殿青, 李景保等. 1951-2014 年洞庭湖水沙阶段性演变特征及驱动因素分析. 水土保持学报, 2017, 31(2) : 142-150, 176.]

[ 2 ] Luo W, Zhang X, Deng ZM et al. Runoff and sediment load transport and cause analysis in Poyang Lake basin over the period 1956-2008. Advances in Water Science, 2014, 25(5): 658-667. [罗蔚, 张翔, 邓志民等. 1956-2008 年鄱阳湖流 域水沙输移趋势及成因分析. 水科学进展, 2014, 25(5):658-667.]

[ 3 ] Deng JQ. GIS-based spatial quantitative analysis on change of sediment deposition and erosion in Muping Lake. Journal of Central South University: Science and Technology, 2007, (5): 1000-1006. [ 邓吉秋. 基于 GIS 的目平湖泥沙冲淤变化 空间定量分析. 中南大学学报: 自然科学版, 2007, (5) : 1000-1006.]

[ 4 ] Gao JF, Zhang C, Jiang JH et al. Changes in sediment deposition and erosion and their spatial distribution in the Dongting Lake. Acta Geographica Sinica, 2001, (3) : 269-277. [高俊峰, 张琛, 姜加虎等. 洞庭湖的冲淤变化和空间分布. 地 理学报, 2001, (3): 269-277.]

[ 5 ] Sun P, Sun YY, Zhang Q et al. Temporal and spatial variation characteristics of runoff processes and its causes in Huaihe Basin. J Lake Sci, 2018, 30(2): 497-508. DOI: 10.18307/2018.0221. [孙鹏, 孙玉燕, 张强等. 淮河流域径流过程 变化时空特征及成因. 湖泊科学, 2018, 30(2): 497-508.]

[ 6 ] Liu Y, Xu GB, Duan Y et al. Multi-time scale wavelet analysis of streamflow and sediment sequences into Hongze Lake. Water Resources and Hydropower Engineering, 2020, 51(2): 128-135. [刘源, 徐国宾, 段宇等. 洪泽湖人湖水沙序列 的多时间尺度小波分析. 水利水电技术, 2020, 51(2): 128-135.]

[ 7 ] Yu BY, Yu YS. Sediment deposition in Hongze Lake. Journal of Sediment Research, 2010, (6): 38-43. [虞邦义, 郁玉 锁. 洪泽湖泥沙淤积分析. 泥沙研究, 2010, (6) : 38-43.]

[ 8 ] Liu Y, Wang Y, Yang XG. Trends in reference crop evapotranspiration and possible climatic factors in the North China Plain. Acta Ecologica Sinica, 2010, 30(4): 923-932. [刘园, 王颖, 杨晓光. 华北平原参考作物蒸散量变化特征及 气候影响因素. 生态学报, 2010, 30(4): 923-932.]

[ 9 ] Yao WY, Ran DC, Chen JN. Recent changes in runoff and sediment regimes and future projections in the Yellow River basin. Advances in Water Science, 2013, 24 (5): 607-616. [姚文艺, 再大川, 陈江南. 黄河流域近期水沙变化及其趋势 预测. 水科学进展, 2013, 24(5): 607-616.]

[10] Mandelbrot BB, Wallis JR. Some long-Run properties of geophysical records. Water Resources Research, 1969, 5(2) : 321 340. DOI: $10.1029 /$ WR005i002p00321.

[11] Wang KQ, Zeng Y, Xie ZQ et al. Change trend of temperature and precipitation in Huaihe River Basin from 1961 to 2008. Scientia Meteorologica Sinica, 2012, 32 (6) : 671-677. DOI: 10.3969/2012jms.0061. [王珂清, 曾燕, 谢志清等. 1961-2008 年淮河流域气温和降水变化趋势. 气象科学, 2012, 32(6): 671-677.]

[12] Zhu SQ, Dou HS eds. Hongze Lake-Water resources and aquatic living resources. Hefei: China Science and Technology Press, 1993. [ 朱松泉, 窦鸿身. 洪泽湖一一水资源和水生物资源. 合肥: 中国科学技术出版社, 1993. ]

[13] Yan DY. Analysis on sand mining management in Hongze Lake. Jiangsu Science \& Technology Information, 2015, (31) : 
49-50. [严登余. 洪泽湖采砂管理分析. 江苏科技信息, 2015，(31)：49-50.]

[14] Ye ZW, Li ZH. Characteristics and trend of areal precipitation in the Hongze Lake basin since 1951. Resources and Environment in the Yangtze Basin, 2010, 19(12) : 1392-1396. DOI: 1004-8227(2010) 12-1392-05. [叶正伟, 李宗花. 1951 年来洪泽湖流域面雨量变化特征与趋势分析. 长江流域资源与环境, 2010, 19(12)：1392-1396.]

[15] Wang H, Mei M, Zhan TS et al. Current situation and prospect of water resources development and utilization in Huaihe River area. Water Resources Planning and Design, 2005, (1): 10, 29-31. [王浩, 梅梅, 詹同涛等. 淮河区水资源开 发利用现状及展望. 水利规划与设计, 2005, (1) : 10, 29-31.]

[16] Shi HL, Hu CH, Wang YG et al. Variation trend and cause of runoff and sediment load variations in Huaihe River. Journal of Hydraulic Engineering, 2012, 43(5): 571-579. [史红玲, 胡春宏, 王延贵等. 淮河流域水沙变化趋势及其成因分 析. 水利学报, $2012, \mathbf{4 3}(5): 571-579$. ]

[17] Mao SM, Xu H. Discussion on the paper "Variation trend and cause of runoff and sediment load variations in Huaihe River”. Journal of Hydraulic Engineering, 2013, 44(7): 880-882. [毛世民, 许吘. 对“淮河流域水沙变化趋势及其成因 分析”一文的商榷. 水利学报, 2013, 44(7):880-882.]

[18] Yu BY, Ni J, Yang XJ et al. Research on hydrodynamic numerical model for main stream of Huaihe River from Fushan to outlet of Hongze Lake. Water Resources and Hydropower Engineering, 2011, 42(8): 38-42. [虞邦义, 倪晋, 杨兴菊等. 淮河干流浮山至洪泽湖出口段水动力数学模型研究. 水利水电技术, 2011, 42(8): 38-42.]

[19] Ruan RZ, Xia S, Chen Y et al. Change of lake nearby Linhuai Town in West Bank of Hongze Lake during 1979-2006. Wetland Science, 2012, 10(3) : 344-349. [ 阮仁宗, 夏双, 陈远等. 1979-2006 年洪泽湖西岸临淮镇附近湖泊变化 研究. 湿地科学, 2012, 10(3) : 344-349.] 